'Ilu. Revista de Ciencias de las Religiones

ISSN: $1135-4712$

http://dx.doi.org/10.5209/ILUR.61032

\title{
Weber, Casaubon y la secularización de Occidente ${ }^{1}$
}

\author{
Juan Ramón Ballesteros Sánchez ${ }^{2}$
}

Recibido: 27 de marzo de 2016 / Aceptado: 19 de junio de 2017

Resumen. Secularización y modernidad son dos fenómenos vinculados en el mundo occidental. Este trabajo estudia la figura de Isaac Casaubon, un estudioso de la Antigüedad del s. XVI y analiza su experiencia religiosa. Casaubon, que vivió en París desde 1600, fue un testigo privilegiado de los primeros momentos del proceso de secularización en Europa.

Palabras clave: Secularización, Max Weber, Isaac Casaubon, calvinismo, Europa moderna.

\section{[en] Weber, Casaubon and the Western world secularization}

\begin{abstract}
Secularization ist a phenomenon connected with modernity in the Western world. This paper focuses on a classical scholar from 16th century, Isaac Casaubon, and explores his religious experience. Casaubon, living in Paris from 1600, was a key witness to the very first moments of securalization in Europe.
\end{abstract}

Keywords: Secularization, Max Weber, Isaac Casaubon, calvinism, Early modern Europe.

Sumario. 1. El relato normal de la secularización de Occidente. 2. Calvinismo y Estado moderno en la secularización de Occidente. 3. La experiencia religiosa de Isaac Casaubon. 4. Conclusiones: religión y política en la secularización de Occidente. 5. Bibiliografía.

Cómo citar: Ballesteros Sánchez, J. R. (2018), Weber, Casaubon y la secularización de Occidente, en Ilu. Revista de Ciencias de las Religiones 23, 305-315.

\footnotetext{
1 Presenté una primera versión de este texto en la mesa "Sociedad y Secularización” del XI Congreso de la Asociación Andaluza de Filosofía: Filosofía y Religión, retos y desafios actuales que se desarrolló en Granada el 9 de septiembre de 2016.

2 Universidad Pablo de Olavide. Sevilla (España).

Correo electrónico: jrbalsan@upo.es
} 
Al despertar Gregorio Samsa una mañana, tras un sueño intranquilo, encontróse en su cama convertido en mostruoso insecto.

Franz Kafka, La metamorfosis, 1915 (trad. J. L. Borges)

\section{El relato normal de la secularización de Occidente}

El relato normal de la historia de Occidente establece que nuestra civilización es la consecuencia de una progresiva secularización. El desarrollo tecnológico, industrial y económico de las sociedades occidentales se ha visto acompañado, causado según la versión radical de este mismo relato, por la secularización de los modos de pensar y de entendernos a nosotros mismos y al universo que nos rodea. Entiendo por "secularización de los modos de pensar" una actitud mental según la cual los fenómenos de la naturaleza, entre los que también se encuentra el hombre, son susceptibles de ser explicados por medio de razonamientos que ponen el énfasis en la consistencia que aportan los argumentos racionales con los que los construimos. ${ }^{3}$ Cualquier especulación está sujeta en nuestro horizonte secularizado a un principio de prueba causal, sea este natural, científico, filosófico, histórico, crítico o lógico. Y este principio es innato al objeto de la especulación. La realidad puede ser reducida, pues, a la comprensión de sus mecanismos causales internos. Todo es producto de los factores que lo constituyen. Este principio de demostración nos vincula al mundo de lo secular. Según el relato normal, la secularización nos proporciona el ancla de la certeza frente a la alternativa del mito y de la religión como fundamento de explicación, alternativa que está en nuestro pasado y que, a diferencia de otras culturas, hemos sabido superar.

Creo que una de las mejores versiones de este relato normal se halla en este "legendario" pasaje de la última sección de La ética protestante y el espíritu del capitalismo de Max Weber (la traducción del cual no está exenta de polémicas):

El estuche ha quedado vacío de espíritu, quién sabe si definitivamente. En todo caso, el capitalismo victorioso no necesita ya de este apoyo religioso, puesto que descansa en fundamentos mecánicos. También parece haber muerto definitivamente la rosada mentalidad de la riente sucesora del puritanismo, la "ilustración", y la idea del "deber profesional" ronda por nuestra vida como un fantasma de ideas religiosas ya pasadas. [...] Nadie sabe quién ocupará en el futuro el estuche vacío, y si al término de esta extraordinaria evolución surgirán profetas nuevos y se asistirá a un pujante renacimiento de antiguas ideas e ideales; o si, por el contrario, lo envolverá todo una ola de petrificación mecanizada y una convulsa lucha de todos contra todos. En este caso, los "últimos hombres" de esta fase de la civilización podrán aplicarse esta frase: "Especialistas sin espíritu, gozadores sin corazón: estas nulidades se imaginan haber ascendido a una nueva fase de la humanidad jamás alcanzada anteriormente." (trad. Luis Legaz Lacambra) ${ }^{4}$

3 Lang 2016 estudia las raíces antiguas de esta concepción. Este párrafo inicial debe mucho a las tesis de este libro magnífico (cfr. Lang 2016, 25).

4 Cfr. Weber 1969, 224-225. El texto original de "La relación entre la ascesis y el espíritu capitalista" apareció en la La ética protestante y el espiritu del capitalismo en 1904-1905. Sobre la polémica que ha generado la traducción inglesa de Talcott Parsons de este pasaje y el nacimiento de la famosa "jaula de hierro" weberiana, vid. 
Weber asoció secularización y vacío en un horizonte de existencia que él percibía como mecánico y carente de espíritu. Gregor Samsa, el "hombre moderno" de Arendt o el "hombre unidimensional" de Marcuse son descendientes de la alienación weberiana. El planteamiento weberiano, desde la lectura que propongo, está en la línea de una comprensión nihilista de la evolución de nuestra civilización.

Una generación más tarde, Ortega y Gasset (en un ensayo sobre teoría de la Historia aparecido originalmente en 1935), encontró los orígenes del relato normal de la secularización de Occidente en el Discurso del método de Descartes: "el canto de gallo del racionalismo (son palabras del propio Ortega), la emoción de alborada que inicia toda una edad, eso que llamamos la Edad Moderna". ${ }^{5}$ Ortega, al igual que Weber, ya se sentía legitimado para elaborar la crítica de la secularización definida por el relato normal: "Esa Edad Moderna de la cual muchos piensan que hoy asistimos nada menos que a su agonía, a su canto de cisne. Y es innegable, por lo menos, que entre el estado de espíritu cartesiano y el nuestro no existe floja diferencia. ¡Qué alegría, qué tono de enérgico desafío al Universo, qué petulancia mañanera hay en [las] magníficas palabras de Descartes!”.

Las palabras de Weber y Ortega y Gasset constituyen los cimientos del relato normal de la secularización de la civilización occidental. Las tomaré como punto de partida para vertebrar un trabajo en el que me propongo revisitar los orígenes históricos de la narrativa sobre la evolución de Occidente que se define a partir de las posturas de ambos. ${ }^{6}$ Para comprender la cuestión de los fundamentos de la secularización occidental propongo analizar desde una misma perspectiva dos cuestiones aparentemente desconectadas. Mi intención es presentar dos procesos históricos contemporáneos a la "petulancia mañanera" cartesiana (Ortega), procesos hasta cierto punto concomitantes, que creo que hay que situar en los orígenes de "la rosada mentalidad de la riente ilustración" (Weber): la definición del austero puritanismo calvinista, por un lado, y la construcción del Estado moderno, por otro. Esta primera parte de mi trabajo se apoya en la experiencia que de ambos procesos tuvo el humanista Isaac Casaubon. Al final del trabajo, a modo de conclusión, mi objetivo es esbozar una crítica al relato normal precisamente a partir de la experiencia casauboniana.

\section{Calvinismo y Estado moderno en la secularización de Occidente}

Denis Crouzet, un historiador francés que ha estudiado los rituales de agresión, el imaginario colectivo y los discursos de la violencia durante los años de las Guerras de Religión de los siglos XVI y XVII, explicó de qué modo el calvinismo y lo que él llamó la "sensibilidad calvinizante" contribuyeron a secularizar los modos de pensa-

Kaesler 2012. Al respecto es también muy instructivo Baehr 2001. La dificultad del texto radica en la traducción del término alemán Gehäuse que según los contextos puede significar "envoltura", "cáscara", "caparazón", "concha", "cofre" o "estuche". La antigua traducción de Luis Legaz que utilizo ha sido criticada por excesivamente esmerada, brillante y retórica (cfr Weber 1998, 75). En este punto, a mi juicio, no es menos desacertada que otras versiones castellanas del texto: José Chávez Martínez (Weber 1979, 109) utiliza "cofre" para traducir el Gehäuse original, Jorge Navarro Pérez (Weber 1998, 259) “jaula" (equivalente a "cage", la traducción inglesa standard del término para este pasaje). Peter Baehr (Baehr 2001) aporta argumentos convincentes para optar por un significado con connotaciones biológicas como "concha" ("shell").

5 Cfr. Ortega y Gasset 1971, 14.

6 Un análisis breve de los hitos fundamentales de este relato en Bremmer 2008. 
miento del europeo medio a partir del siglo y medio que duró el conflicto religioso en Francia. ${ }^{7}$ Según Crouzet, el calvinismo limitó la esfera de lo sagrado al acotar la intervención divina en el mundo terrenal al momento de la revelación bíblica. Con ello el calvinismo trazó una frontera frente a la hipertrofia de lo sagrado, la respuesta católica a la herejía protestante. Los dogmas calvinistas de la predestinación y de la no remisión del pecado original, la abolición de la intercesión y la transubstanciación, o la limitación de la salvación a la fe en un Dios incomunicable al hombre son interpretados por Crouzet como reacciones frente a los fenómenos de angustia y crispación escatológica colectiva generados por la inminencia del Juicio. Esos principios teológicos dotan de modernidad secular a la Reforma de Calvino. El calvinista se sabe "irrémédiablemente coupé de Dieu par l'ignominie du peché" (p.149) y contempla toda la pirotecnia católica para la salvación (ayunos, penitencias, oraciones, novenas, romerías, procesiones...) con la repugnancia y el rechazo que provocan los actos supersticiosos e idolátricos. De este modo, la contracción de lo sagrado propiciada por la "sensibilidad calvinizante" se encuentra en la genealogía del capitalismo y, por ende, en la del vacío weberiano.

La construcción del Estado moderno, al igual que la reforma protestante en su versión calvinista, también ha sido percibida como una etapa en el proceso de secularización de Occidente. Nicolas Le Roux, un historiador especializado en la historia de la corte y la nobleza francesa en el Antiguo Régimen, ha relacionado los cambios políticos operados en la Europa moderna con la creación de un mundo más secularizado. ${ }^{8}$ La restricción de la experiencia religiosa a ciertos edificios y momentos, la reclusión de la religión a la esfera de lo privado, el fin de la confesionalización de la acción política, todo ello tal y como fue establecido por los politiques en el discurso que justificó la coronación de Enrique de Navarra como Enrique IV de Francia, constituyen balizas necesarias en la fundación del Estado moderno. Esta sección del relato normal se sostiene sobre la aceptación de dos esferas bien diferenciadas e independientes en la vida y la acción del hombre occidental: la esfera cívica en la que el ciudadano está sujeto a la ley humana y la esfera religiosa en la que el creyente se somete a normas de origen divino. Es decir, en la Europa moderna se inició la historia del consenso generalizado con el que distinguimos hoy en día entre pecado y delito, entre ciudadano y fiel, entre Estado y confesión religiosa. Esta distinción estuvo acompañada a partir del s. XVI por cambios cualitativos en el funcionamiento de los Estados occidentales: la racionalización y profesionalización de la administración y la burocracia, la consolidación de la soberanía monárquica, la centralización del Estado y de sus órganos de gobierno.

\section{La experiencia religiosa de Isaac Casaubon}

Inicialmente la biografía de Isaac Casaubon (1559-1614) responde completamente a las tesis de Crouzet y de Le Roux. Casaubon, calvinista convencido, vivió su experiencia religiosa de un modo discreto, tanto que católicos y protestantes le reprocharon por igual no hacer demostraciones más vehementes de pertenencia confesional. Fue también un resuelto partidario político de Enrique IV a pesar de la

He utilizado fundamentalmente Crouzet 1990 y Crouzet 2008.

Cfr. Le Roux 2009. 
conversión de este al catolicismo romano, tanto que aguardó a su trágica desaparición (fue asesinado en 1610), para abandonar Francia e instalarse en la Inglaterra de Jacobo I Estuardo donde vivió los últimos años de su vida. Casaubon es un personaje bien conocido en ámbitos académicos relativamente especializados. Fue uno de los grandes filólogos clásicos de su tiempo y, al final de su vida, un polemista comprometido contra la versión católica de la Historia sagrada. Miembro de una familia hugonote instalada en Ginebra, en 1597 regresó a Francia con la intención de entrar al servicio del rey Enrique IV. Desde su condición de erudito que trabajaba como bibliotecario del rey se convirtió, de un modo quizá involuntario, en una pieza muy bien informada del proceso de normalización política y religiosa diseñado por la monarquía. ${ }^{9}$

Además de con un abundante epistolario y de su obra científica, para conocer a Casaubon contamos con un documento muy excepcional. Desde su regreso a Francia, primero en Montpellier y más tarde en París, Casaubon escribió un diario personal: las Ephemerides. Este tipo de documento no es extraño en la época. Disponemos de memorias y diarios de otros personajes contemporáneos. ${ }^{10}$ Los Ensayos de Montaigne, por ejemplo, rozan el género del diario y son prácticamente contemporáneos al diario de Casaubon. La filosofía de Descartes y la consolidación de la identidad individual como fundamento de su pensamiento suponen, de alguna manera, la coronación filosófica de este género autobiográfico. Lo que hace de las Ephemerides de Casaubon un diario extraordinario es que Casaubon decidió que Dios sería el interlocutor con el que iba a intercambiar sus confesiones íntimas. Todo el diario es, en efecto, una conversación con Dios. En las Ephemerides se expresan ansias de conocimiento (y de libros), proyectos científicos, molestias domésticas (hijos, visitas...), conversaciones con el rey y todo tipo de reflexiones personales. Las Ephemerides de Casaubon han sido muy utilizadas por los historiadores de la filología clásica y del reinado de Enrique IV. Me propongo utilizar varios pasajes de este diario para entender la posición de Casaubon en el contexto de secularización política y religiosa que vengo presentando.

Casaubon se estableció en marzo de 1600 en París, una de las ciudades más fervorosamente católicas de la Cristiandad. En París tuvo que aprender a convivir con toda la parafernalia barroca del catolicismo postridentino. Una incómoda proliferación de la iconografía católica de lo divino dominaba el ritmo de la vida de la ciudad $y$, por mucho que maese Casaubon quisiera vivir al margen de lo que un calvinista debía interpretar como puro paganismo, misas, rogatorias y procesiones se colaban en su vida cotidiana, causándole en algunas ocasiones sorpresa y en otras, indignación. El París de Enrique IV era una Babilonia repleta de idolatría que no podía menos que disgustar a un calvinista convencido. Voy a presentar algunos ejemplos de los horrores a los que tuvo que acostumbrarse la sensibilidad calvinista de Casaubon en la ultramontana París.

El primero de noviembre de 1600, pocos meses después de su llegada a París, un rito católico despertó la curiosidad siempre alerta de Casaubon, tanto como para alterar la rutina de lectura y estudio que seguía en su casa y anotar lo siguiente en su diario:

\footnotetext{
9 He estudiado la figura de Casaubon en dos trabajos recientes: Ballesteros 2016 y Ballesteros [en prensa]. Sobre Casaubon, vid. Pattison 1892, Hamilton 2009, Parenty 2009 o Grafton-Weinberg 2011.

10 Por ejemplo, las Memorias de Roissi o los Diarios de L'Estoile, que utilizaré más adelante.
} 
[...] por la mañana dedicamos muchas horas al estudio. También invertimos con provecho no poco tiempo después de comer, pero el ruido de todas las campanas de París que celebra hoy el día de los difuntos nos hizo salir de casa. Lo hacen para que a media noche las almas se liberen del suplicio de las llamas del purgatorio. Oh Dios, Padre de la verdad, ¿ves estas cosas y las permites? ${ }^{11}$

Aquellas campanadas no sólo anunciaban dogmas que los calvinistas no compartían, como el del purgatorio, sino que planteaban a Casaubon un ritual cívico del que era difícil abstraerse. La curiosidad que la fiesta de Todos los Santos de 1600 despertó en Casaubon, se convirtió en asombro e indignación el día de la procesión del Corpus de 1601:

Perdimos parte de la mañana contemplando las riquezas de París. Era, en efecto, el día en que toda la ciudad se echa a la calle para rendir culto a la oblea de pan como si fuera Dios. ¡Qué cosa tan asombrosa!... y, según dicen, aquí es menos exaltada que en Roma. Al Papa lo llevan a hombros cuatro hombres y el pan lo porta un caballo blanco llevado al trote. ¡Ay piedad! Por Dios, ¿cuánto tiempo más lo van a seguir haciendo? ${ }^{12}$

La consagración del Corpus Christi estaba, de nuevo, completamente al margen de los principios calvinistas, pero era la dimensión social y festiva de la celebración lo que llamó la atención en este turista in partibus infidelium. Casaubon clamaba a Dios ante la idolatría que empapaba todos los momentos de la vida en la ciudad.

Pero, desde luego, a los ojos de Casaubon nada se podía comparar con el ceremonial que implicaba el rito romano de la misa. En julio de 1601, no sabemos muy bien bajo qué circunstancias ni en qué lugar, Casaubon asistió a una misa (pienso que debió ser un gesto de buena voluntad de Casaubon hacia el creciente entorno católico del rey que trataba de tender puentes, ya veremos cómo, con los calvinistas de la Corte). Casaubon dedicó dos líneas para resumir en su diario aquella experiencia transconfesional:

Por la mañana, primero mis estudios y después asistí desde lejos a los solemnes rituales de la misa. ¡Por Dios! ¿Acaso son en algo diferentes a un teatrillo cómico? Padre de la luz, te pido que des vista a los que no ven. Amén. ${ }^{13}$

En febrero de 1602, en París se celebró un nuevo ritual cívico: los Carnavales, que colmaron la paciencia de Casaubon y lo enfurecieron hasta el siguiente extremo:

Hoy se han celebrado los Carnavales. Detestamos tal desvergüenza con toda el alma y la juzgamos absolutamente intolerable para los cristianos. Decidimos no poner el pie en la calle, pero como recibí la invitación del consejero real, Señor Gourges, tuvimos que perder algunas horas fuera de casa. ${ }^{14}$

11 Traduzco a partir de la edición de John Russell (cfr. Casaubon 1850). Este pasaje en concreto es Casaubon 1850 , 308.

12 Cfr. Casaubon 1850, 355-356.

13 Cfr. Casaubon 1850, 359.

14 Cfr. Casaubon 1850, 409. 
La vida cívico-religiosa del París de Casaubon estaba transida de falsa sacralidad. La reacción de Casaubon no fue integrar ese universo en su manera de vivir, sino marginarse del mismo e intentar excluir de sus rutinas la más mínima participación en unas prácticas que pudieran contaminarle. Ni Casaubon, ni la versión calvinista del cristianismo que él profesaba y que según algunos preparó la secularización de Occidente, son ejemplos de concordia religiosa, sino de acatamiento de una actitud social forzada por las circunstancias: la tolerancia impuesta desde el poder político. Y aunque Casaubon hubiera sido atraído a la capital por el Rey y estuviera protegido por la política de coexistencia religiosa que la monarquía trataba de impulsar, había un espacio religioso intangible en el seno de Casaubon al que la voluntad regia no tenía acceso: la convicción de tener a Dios y la verdad de su parte.

La política regia no era ni mucho menos equidistante en lo relativo a las confesiones religiosas. Enrique IV había aceptado su conversión al catolicismo en aras de la pacificación interior. Lo hizo por razones puramente prácticas: el $90 \%$ de la población francesa era católica y la pacificación interior todavía no podía hacerse sin una toma de partido confesional por parte de la propia monarquía. En la política de normalización desplegada por la monarquía se impuso una forma de convivencia religiosa por medio del famoso edicto de Nantes firmado en 1598, cinco años después de la conversión al catolicismo romano del rey. El edicto de Nantes estableció la cohabitación de las confesiones en el reino, pero la cara de esa cohabitación fue diferente en cada región. Por ejemplo, desde la proclamación del edicto, llamado de tolerancia, el culto reformado quedó prohibido en la capital del reino. A los calvinistas parisinos tan sólo les estaba permitido celebrar reuniones religiosas, las llamadas cenas, en dos suburbios a las afueras de la ciudad: en Charenton y en Ablon. Casaubon intentaba acudir regularmente al culto en Ablon-sur-Seine, para lo cual debía realizar cada domingo junto a sus correligionarios un molesto viaje de unos 15 kilómetros hacia el sur de París. En el mejor de los casos podía realizarlo en barca por el Sena o en la carroza de algún conocido. No siempre le era posible asistir a los oficios. El domingo 24 de junio de 1601 fue uno de esos días. En su diario dejó escrito cómo modificó aquel día su severo plan de trabajo (por aquellos días Casaubon estaba trabajando en la edición de la Historia Augusta, una colección de biografías de emperadores romanos del s. IV) y consagró el día a una lectura bíblica:

Como no pudimos ir a Ablon, cosa que tanto deseábamos, apacentamos el alma con la lectura de los textos sagrados, y parece que haciéndolo esta comienza a reponerse de su postración. Leímos, según lo previsto, los últimos capítulos de Jeremías y sus Lamentaciones.

Casaubon dedicó aquel domingo a la lectura del profeta Jeremías. De hecho, en las fechas en las que decidió instalarse en París también leyó otros textos del exilio como Ezequiel e Isaías. En Jeremías se cuenta la conquista de Israel por Nabucodonosor y el destierro en Babilonia del pueblo de Israel. La parte más dramática del texto, a la que se refiere inmediatamente Casaubon, es la que narra el asedio de Jerusalem:

¡Ay divino profeta! ¡Asunto realmente digno de lamentación! ¡Ay pueblo duro de cerviz! ¿A qué tanta obstinación contra Dios? ¿A qué tanta ansia de perecer? Ni las advertencias de los profetas, ni las amenazas de Jehová, ni el peligro inminente 
pudieron hacer que el pueblo infeliz se volviera a Dios. ¿Por qué en las máximas penurias en que se encontraba, me refiero al asedio, cuando aún les quedaba la posibilidad de la penitencia, no dejaron de juntar un crimen con otro? Pereciste, pueblo infeliz, pereciste completamente y, según te hiciste merecedor tiempo atrás, alcanzaste, en fin, tu destrucción. Pero esto se escribió para nuestra enseñanza. ¿Habrá algún pueblo o individuo que imite a los judíos? ${ }^{15}$

La proyección sobre la Historia bíblica de su propia experiencia, política y religiosa, es una constante en las Ephemerides, de modo que la lectura del diario plantea la permanente (y fascinante) necesidad de desentrañar las alusiones y dobles lecturas que los textos proponían a Casaubon. Además de este hecho, del texto que acabo de citar me interesa destacar un aspecto que volveremos a encontrar más adelante: la intensificación de la experiencia religiosa vivida por Casaubon y la voluntad de plegarse por completo a la voluntad de Dios tal y como él creía encontrarla en los textos.

La ley de Dios estaba muy vigente en el corazón de Casaubon (lo acabamos de ver), pero a la vez Casaubon era testigo de cómo la ley de los hombres se erigía en pos de la armonía política y social. El caso de la conversión al catolicismo romano de un viejo amigo de Casaubon, un caso muy sonado de apostasía, permite entender los métodos con los que la monarquía de Enrique IV se propuso construir un Estado por encima del conflicto religioso y cómo Casaubon percibió estos cambios.

Philippe Canaye, señor de Fresne, abjuró de los errores del calvinismo el 10 de abril de 1601. Canaye era un diplomático hábil que militó en el partido hugonote de Enrique IV durante la guerra civil. También era un docto conocedor de los clásicos. Su decisión de abjurar fue interpretada por sus contemporáneos como la consecuencia de un cálculo que respondía al interés de promoción personal. Pierre de L'Estoile (1546-1611), jurista bien informado y testigo de los acontecimientos, calificaba a Canaye como "más ambicioso que rico, por lo que se inclinó del lado en el que los vientos soplaron más a propósito de sus propios intereses". ${ }^{16}$ De hecho la conversión de Canaye estuvo precedida por una entrevista con el rey y seguida de su nombramiento como embajador francés en la Serenísima República de Venecia. Esta es la versión convencional de la conversión de de Philippe Canaye, en cambio también es posible analizar su caso desde la perspectiva del relato normal de la secularización. Con un cambio de perspectiva, el apóstata deja de ser un habilidoso oportunista y se convierte en un ejemplo de los nuevos tiempos: la personificación de un compromiso individual con la construcción de un Estado sólido al margen de fronteras religiosas. De hecho, no parece que la conversión de Canaye revistiera grandes cambios en sus convicciones religiosas, más allá de la aceptación de las formalidades propias de la nueva confesión..$^{17} \mathrm{~A}$ su muerte, por ejemplo, fue enterrado en su casa solariega de Fresne con una modestia impropia de la ambición que le atribuyeron sus detractores "sans aucune cérémonie ou solennité". ${ }^{18}$ Casaubon en cambio no estaba dispuesto a olvidar la barreras confesionales:

\footnotetext{
Cfr. Casaubon 1850, 356-357.

Cfr. L'Estoile 1958, 20.

Es lo que se deduce de su correspondencia diplomática, cfr. Regnault 1635-1636.

Cfr. L'Estoile 1960, 36.
} 
¿Qué decir de mi antiguo Pílades? Me refiero a Philippe Canaye de Fresne quien, a pesar de haber conocido la verdad y de profesarla durante tantos años, ha renunciado a ella recientemente y, arrogante, se ha vuelto hacia el vómito. Sabes Dios, que conoces el fondo de mi corazón, cuánto me ha afectado esta decisión, tanto porque estimamos que este hombre ha violado la majestad de tu Divinidad como porque al conocerse públicamente la amistad que compartíamos, muchos dan por hecho que vamos a emular en breve el acto de perfidia contra Dios que ha cometido aquel. Pero que me trague la tierra diez mil veces, si esto pudiera ocurrir, antes que cambiar una iota de la verdad que conozco. Por lo demás, nuestra antigua amistad no sólo ha quedado disuelta sino erradicada en cuanto hemos sabido del acto de Canaye. Ya hace casi un mes desde que lo vimos por última vez y, después de esto, no hacemos esfuerzo alguno en verlo. ${ }^{19}$

Es como si dentro de Casaubon los cambios que se estaban operando en la sociedad francesa supusieran una batalla entre dos fidelidades contrapuestas, como si la del Rey y la de Dios no fueran dos esferas de actuación independientes sino dos alternativas excluyentes, no complementarias. Consideremos esta declaración de principios redactada en el momento en que Casaubon se instalaba en la Corte:

Confieso que cada vez que pongo ante mis ojos el cisma que desde hace tantos años lacera a tu Iglesia se apodera de mí un enorme deseo de paz y concordia. Pero jamás llegamos a la locura de creer que haya que anteponer una paz injusta e irreligiosa incluso en el actual estado de cosas..$^{20}$

Creo que lo que inhabilita a Casaubon como personaje en nuestra historia normal de la secularización es su incapacidad de convertir en privada su experiencia religiosa y su voluntad de integrar absolutamente sus convicciones religiosas en su vida y comportamiento social. Casaubon era un integrista en la medida que consideraba intangible la doctrina religiosa. ${ }^{21}$ Ese integrismo se apoyó también en la completa certidumbre de que existe una verdad absoluta, que excluye cualquier negociación sobre su propia naturaleza:

Ojeaba ocasionalmente a Gregorio de Nacianzo y tomé esta frase de su Apologético para mi propio uso: La opinión aleja del ser a la mayoría y la vanagloria es un gran impedimento para los hombres en busca de virtud.

La opinión obstaculiza el progreso. ${ }^{22}$

La duda sobre las propias convicciones y el continuo cuestionamiento de la verdad convierte en precaria cualquier argumentación que en un mundo secularizado estemos en condiciones de elaborar. Casaubon no estaba dispuesto a convertir en

19 Cfr. Casaubon 1850, 346. En este texto hay una cita de un verso de la Ilíada (cfr. Hom. Il. 4.182). La amistad de Casaubon y Canaye se remonta a los años ' 80 del s. XVI. En 1587 Casaubon dedicó a Canaye su edición anotada del Nuevo Testamento, en 1595 la de las Vidas de Suetonio. Sobre la política hugonote de Enrique IV, vid. Daussy 2002.

20 Cfr. Casaubon 1850, 275-276.

21 Sólo al final de su estancia parisina, Casaubon comenzó a plantearse dudas sobre cuestiones de fe, cfr. Ballesteros 2016,125, n. 83 .

22 Cfr. Casaubon 1850, 281. La cita del Apologético de Gregorio de Nazianzo se encuentra en GN Apol. 51. 
precaria su fe en Dios. Sobre cómo en Occidente hemos digerido esa precariedad que Casaubon no estuvo dispuesto a admitir, quisiera construir mis conclusiones.

\section{Conclusiones: religión y política en la secularización de Occidente}

El relato normal de la secularización de Occidente es también el relato de la precarización de sus convicciones. Según el relato normal, la deconstrucción, el relativismo, la postmodernidad, el pensiero debole han sido los destinos del camino que nos ha permitido entender el mundo en los términos mundanos y de causalidad interna que presenté más arriba. Este capítulo de la macronarrativa que trato de reconstruir y criticar incide sobre el aspecto intelectual de la secularización, pero no valora suficientemente, desde mi punto de vista, una serie de cambios en el terreno político que hemos visto comparecer en la Francia de Casaubon.

Si el horizonte religioso del europeo se volvió precario con la Reforma, la construcción del Estado moderno que contemporáneamente se estaba operando le ofreció otros espacios de estabilidad. Un ejercicio más agudo de la autoridad propio de la monarquía absoluta y la consiguiente exaltación de la majestad monárquica, son dos evoluciones que permitieron que el orden político sustituyera, en su dimensión sacral, al religioso. A partir del mundo moderno asistimos a una transferencia de sacralidad desde el universo de la religión al de la política, con lo que el Estado ocupa el lugar que la religión tenía en el orden natural de la vida humana previo a la Reforma. Nuestro mundo secularizado es un mundo en el que más que un repliegue de lo sagrado se ha producido una redefinición de lo sagrado. Creo que en lugar de vaciar el estuche lo que hemos hecho es depositar el contenido del mismo en otro recipiente más convincente. Y lo hemos hecho sin alterar sustancialmente la calidad de lo que en él hemos decidido guardar.

\section{Bibliografía}

Baehr, P., 2001, "The "Iron Cage" and the "Shell as Hard as Steel": Parsons, Weber and the Stahlhartes Gehäuse Metaphor in the Protestant Ethic and the Spirit of Capitalism", History and Theory 40.2, 153-169.

Ballesteros, J. R., 2016, “Casaubon en París: La anotación de la Historia Augusta (1603) en la polémica religiosa de tiempos de Enrique IV de Francia”, Quaderni di Storia 84, 83126.

Ballesteros, J. R., en prensa, “"In the tents of Kedar" (Ps 120:5): Scholarship as Martyrdom in Paris during Henry IV”, I. Pérez y M. Penzi (eds.), Catholic martyrdom and hispanofilia.

Bremmer, J. H., 2008, “Secularization: Notes toward a Genealogy", en Vries, H. de (ed.), Religion. Beyond a Concept, New York, 432-437.

Casaubon, I, 1850, Ephemerides Isaaci Casauboni, (J. Russell, ed.), 2 vols., Oxford.

Crouzet, D, 1990, Les Guerriers de Dieu. La violence au temps des troubles de Religion (vers 1525-vers 1610), París.

Crouzet, D, 2008, Dieu en ses royaumes. Une Histoire des Guerres de Religion, París.

Daussy, H, 2002, Les Huguenots et le Roi. Le combat politique de Philippe Duplessis-Mornay (1572-1600), Ginebra. 
Grafton, A. y Weinberg, J, 2011, "I have always loved the Holy Tongue”. Isaac Casaubon, the Jews and a Forgotten Chapter in Renaissance Scholarship, Cambridge-Londres.

Hamilton, A., 2009, "Isaac Casaubon the Arabist: Video longum esse iter", Journal of the Warburg and Courtauld Institutes 72 (2009), 143-168.

Kaesler, D, 2012, "Ein „,stahlhartes Gehäuse“ ist kein „Iron Cage“. Über Forscher, die kein Deutsch können”, http://literaturkritik.de/public/rezension.php?rez_id=16239 [acceso: 18.08.2016].

Lang, Ph., 2016, Science. Antiquity and Its Legacy, Oxford.

Le Roux, N., 2009, Les Guerres de Religion (1559-1629), París.

L'Estoile, P. de, 1958, Journal de L'Estoile pour le rège de Henri IV. Vol. 2 (1601-1609), (A. Martin, ed. y not.), París.

L'Estoile, P. de, 1960, Journal de L'Estoile pour le rège de Henri IV et le début du règne de Louis XIII. Vol. 3 (1610-1611), (A. Martin, ed. y not.), París.

Ortega y Gasset, J., 1971, La Historia como sistema, Madrid.

Parenty, H., 2009, Isaac Casaubon helléniste. Des studia humanitatis à la philologie, Ginebra. Pattison, M., 1892, Isaac Casaubon (1559-1614), Oxford.

Regnault, R., 1635-1636 (ed.), Lettres et Ambassade de Messire Philippe Canaye Seigneur de Fresne, 3 vols., París.

Weber, M., 1969, La ética protestante y el espíritu del capitalismo, (Legaz Lacambra, L., trad.), Barcelona.

Weber, M. 1979, La ética protestante y el espíritu del capitalismo, (Chávez Martínez, J., trad.), México.

Weber, M. 1998, La ética protestante y el espíritu del capitalismo, (Navarro Pérez, J, trad.), Madrid, 1998. 
